\title{
Metodologia de Análise de Redes do Cotidiano num Serviço Residencial Terapêutico: um estudo de caso
}

\author{
The Everyday Networks Analysis Method at an Assisted Residential Service: a case study
}

Metodología de Análisis de Redes del día a día en un Servicio Residencial Terapéutico: un estudio de caso

Luciane Prado Kantorski ${ }^{1}$, Ariane da Cruz Guedes², Jandro Moraes Cortes ${ }^{3}$, Vanda Maria da Rosa Jardim4, Valéria Cristina Christello Coimbra ${ }^{5}$, Michele Mandagará de Oliveira ${ }^{6}$

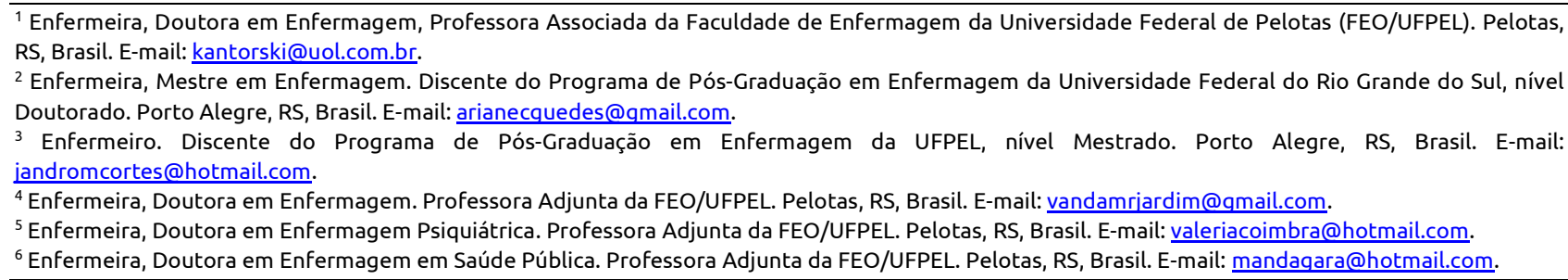

\section{RESUMO}

O presente trabalho é um estudo sobre a aplicação da Metodologia de Análise de Redes do Cotidiano (MARES) com moradores de dois Serviços Residenciais Terapêuticos de Caxias do Sul-RS. Trata-se de um recorte da pesquisa "Redes que reabilitam: avaliando experiências inovadoras de composição de redes de atenção psicossocial". O objetivo foi compreender as redes sociais e de serviços dos moradores do Serviço Residencial Terapêutico a partir da aplicação da metodologia mencionada. Utilizaram-se dados das entrevistas e dos grupos focais realizados com onze moradores, coletados em maio de 2010. A aplicação da MARES se desencadeou em três momentos: Mapeamento da Rede de Serviços, da Rede de Sociabilidade, e Construção do Mapa da Pessoa - individual e coletivo. A análise permitiu visualizar e compreender as interações e articulações dos moradores com o território, que contribuem para sua reinserção social. A utilização da metodologia possibilitou valorizar experiências do cotidiano e compreender a construção das redes.

Descritores: Saúde Mental; Serviços de Saúde Mental; Metodologia; Enfermagem Psiquiátrica.

\section{ABSTRACT}

The present study addresses the application of the Everyday Network Analysis Method (MARES, as per its acronym in Portuguese) developed by residents of two Assisted Residential Services in Caxias do Sul, Rio Grande do Sul, Brazil. This paper is an excerpt of the study "Networks that rehabilitate: evaluating innovative experiences of comprising psychosocial care networks". The objective was to understand the social and service networks of residents of Assisted Residential Services by applying the referred methodology. Data were collected from interviews and focal groups with eleven residents in May 2010. The MARES method was applied in three steps: Mapping the Service Networks, the Sociability Network, and Constructing the Map of the Person-individual and collective. The analysis permitted to see and understand the interactions of residents with the territory, which contributes with their reinsertion to society. Using this methodology allowed for valuing everyday experiences and understanding how networks are formed.

Descriptors: Mental Health; Mental Health Services; Methodology; Psychiatric Nursing.

\section{RESUMEN}

Estudio sobre la aplicación de la Metodología de Análisis de Redes Sociales (MARES), realizada con residentes de dos Servicios Residenciales Terapéuticos de Caxias do Sul-RS. Recorte de la investigación "Redes que rehabilitan: evaluando experiencias innovadoras de composición de redes de atención psicosocial". Se objetivó interpretar las redes sociales y de servicios de los residentes de los Servicios a partir de la metodología. Se utilizaron datos de entrevistas y de grupos focales organizados con 11 residentes, recolectados en mayo de 2010. La MARES fue aplicada en tres momentos: Mapeo de la Red de Servicios, de la Red de Sociabilidad y Construcción del Mapa Personal -individual y colectivo-. El análisis permitió visualizar y entender las interacciones y articulaciones de los residentes con el ambiente, que colaboran con su reinserción social. El uso de la metodología posibilitó valorizar experiencias del día a día y comprender cómo se construyen las redes.

Descriptores: Salud Mental; Servicios de Salud Mental; Metodología; Enfermería Psiquiátrica. 


\section{INTRODUÇÃO}

A Metodologia de Análise de Redes do Cotidiano (MARES) trata-se de um método fenomenológico, interacionista e construcionista a ser utilizado para analisar redes sociais do cotidiano, em geral, e redes de usuários dos serviços públicos, em particular, com o objetivo de mapear as redes existentes, as redes em formação ou as redes potenciais, identificando os problemas que inibem a expansão da rede e os meios de superação dos problemas ${ }^{(1-2)}$.

É um método fenomenológico na medida em que busca verificar a rede a partir da experiência dos atores no cotidiano; é um método interacionista ao valorizar na experiência do sujeito no mundo da vida, as trocas sociais, de dons que circulam, as regras de reciprocidade que explicam os conflitos e as alianças; é um método construcionista, na medida em que leva os atores participantes a refletirem sobre a experiência em rede e de se apropriarem desta reflexão visando identificar saídas para os problemas por eles identificados(1-2).

Existem alguns desafios para aplicar a noção de rede nos espaços públicos de usuários, a saber: superar a compreensão funcionalista de rede que impede apreender os aspectos intersubjetivos das práticas sociais; entender o caráter relacional das redes; qualificar a rede de usuários (como aquele que usa e se apropria dos recursos das políticas distributivistas do Estado) como diferente da rede de cidadão; entender que a rede de usuários é diferente daquela rede social por se constituir nos espaços intermediários entre Estado, sociedade civil e mundo da vida(1-2).

A MARES é uma metodologia de cunho qualitativo, a qual busca resgatar a complexidade simbólica das práticas sociais entrelaçadas em sistemas interativos sobrepostos que articulam as regiões da moral, da afetividade, da associação espontânea, do direito e da coresponsabilidade na esfera pública. Essa metodologia diferenciada encerra uma reação normativa e sociológica contra as estratégias utilitaristas e reducionistas, às quais reduzem a análise das práticas a alguns modelos analíticos validados em indicadores superficiais como densidade e tamanho, mas que não contemplam a complexidade dos sistemas de relacionamentos e de trocas nos campos do mundo da vida(2).

Esta se encontra ancorada no referencial teórico proveniente das Ciências Sociais, tendo como cerne o ideal antiutilitarista. O interesse em evidenciar o pensamento antiutilitarista requer um diálogo da sociologia com as mudanças paradigmáticas das disciplinas afins e, por outro lado, a elaboração de um pensamento complexo no contexto da sociologia o qual dê conta de responder os novos desafios postos pelas mudanças simbólicas e materiais dos bens circulantes e pelos processos de organização espacial e temporal da sociedade moderna ${ }^{(1)}$.

A questão do antiutilitarismo, enquanto movimento intelectual e cultural teve início na Europa, mais especificamente na França, no ano de 1981. Portanto, é resultado da articulação de pensadores empenhados com a crítica articulada e sistemática ao utilitarismo econômico. Este foi denominado de M.A.U.S.S. Mouvement Anti-Utilitariste dans les Sciences Sociales (Movimento Anti-Utilitarista nas Ciências Sociais), sob a tradição teórica de Marcel Mauss. Sendo assim, nesse âmago a dádiva é centralizada como figura sociológica principal para a fundamentação de uma crítica intensa ao utilitarismo ${ }^{(3)}$.

A Metodologia de Análise de Redes do Cotidiano (MARES) desenvolvida por Paulo Henrique Martins ${ }^{(2)}$ foi utilizada como referencial na pesquisa REDESUL, pois esta permite que o usuário do serviço seja compreendido como o sujeito principal no processo de investigação.

Os novos dispositivos e novos serviços em saúde mental requerem a construção de novos modos de compreender, interpretar, aferir e avaliar a produção de subjetividades, tendo em vista que os modelos arcaicos são insuficientes para dar conta desses novos objetivos e projetos. Sendo assim, nas cooperativas, centros de convivências, empresas sociais, serviços de saúde mental, residências e outras estratégias da Reforma Psiquiátrica devem atuar modos de avaliar serviços que sejam sensíveis às diversas inovações instituídas nestes contextos $^{(4)}$.

Anteriormente à implementação das políticas de saúde mental não eram disponibilizadas alternativas além do hospital psiquiátrico, as opções de cuidado se extinguiam no contexto dessa instituição. Entretanto, a instituição dos Serviços Residenciais Terapêuticos (SRT) foi um importante avanço para a qualidade de vida dos usuários de saúde mental(5).

Sabe-se que os SRT's constituem-se numa nova opção de moradia para indivíduos que permaneceram um longo 
tempo internados em hospitais psiquiátricos, e que em virtude disso perderam completamente a sua individualidade e toda forma de expressão que pudesse traduzir a sua subjetividade.

Portanto, a MARES aplica-se ao contexto do SRT, pois busca captar novos sentidos de subjetividades os quais não podem ser traduzidos num processo avaliativo comum.

O presente artigo trata da construção metodológica de uma pesquisa de avaliação de experiências inovadoras de composição de redes de atenção psicossocial que estão localizados no estado do Rio Grande do Sul, conhecida como REDESUL, financiada pelo Edital MCTCNPq/CT-Saúde/MS-SCTIE-DECIT/33/2008, que em sua etapa qualitativa utilizou-se da MARES, desenvolvida e sistematizada pelo sociólogo Paulo Henrique Martins ${ }^{(1-2)}$.

Portanto, este artigo tem como objetivo compreender as redes sociais e de serviços dos usuários do Serviço Residencial Terapêutico de Caxias do Sul-RS, a partir da aplicação da Metodologia de Análise de Redes do Cotidiano (MARES).

\section{METODOLOGIA}

Trata-se de um estudo sobre a aplicação da Metodologia de Análise de Redes do Cotidiano (MARES), desenvolvida com moradores de dois Serviços Residenciais Terapêuticos no contexto do estudo de caso de Caxias do Sul, no Rio Grande do Sul no mês de maio de 2010, e faz parte da pesquisa REDESUL: Redes que reabilitam - avaliando experiências inovadoras de composição de redes de atenção psicossocial.

O estudo de caso apresenta características importantes, a saber: visar à descoberta, enfatizar a interpretação em contexto, buscar retratar a realidade de forma completa e profunda, usar uma variedade de fontes de informação, revelar experiências de vida e permitir generalizações naturalísticas, procura representar os diferentes e às vezes conflitantes pontos de vista, presente numa situação social e utiliza uma linguagem e uma forma mais acessível do que os outros relatórios de pesquisa(6).

O estudo de caso é uma investigação empírica que aborda um fenômeno contemporâneo dentro de seu contexto de vida real, especialmente quando os limites entre o fenômeno e o contexto não estão definidos. A investigação através do estudo de caso visa apreender uma situação tecnicamente única baseando-se em várias fontes de evidência. Este proporciona que os dados convirjam num triângulo e beneficiem-se do desenvolvimento prévio de proposições de importância na pesquisa avaliativa, elucidando sua potencialidade em descrever o contexto real em que se dá a intervenção e a sua capacidade em explorar situações específicas. Isto não seria possível somente pela análise dos resultados, por identificar na realidade estudada interrelações entre pressupostos e práticas concretas de serviços e $\operatorname{programas}^{(7)}$.

Рara o presente artigo utilizou-se, preliminarmente, os dados coletados por meio de entrevistas com 11 moradores de dois SRT's de Caxias do Sul-RS, denominados SRT 1 e 2, e três grupos focais. Os critérios de inclusão dos sujeitos foram definidos por ser morador do SRT.

O grupo focal é uma técnica utilizada em pesquisas qualitativas, quando o objetivo do pesquisador é verificar como os sujeitos do estudo avaliam uma experiência, uma ideia ou evento; saber suas opiniões, sentimentos e significados sobre um determinado fato, saber como os sujeitos definem um problema e suas opiniões sobre ele. Há no grupo focal o desempenho de seis funções, que são as funções de moderador, relator, observador, operador de gravação, transcritor de fitas e digitador ${ }^{(8)}$.

A MARES compreende o Mapeamento da rede de serviços, de sociabilidades e a construção do mapa da pessoa. No mapeamento da rede serviços levou-se em consideração os chamados condicionantes macrossociológicos, designados pelas Unidade Básica de Saúde, Centro de Atenção Psicossocial, instituições estatais, igrejas, associações comunitárias. No mapeamento da rede de sociabilidades considerou-se os então chamados condicionantes microssociológicos, designados como a família, os vizinhos, a comunidade ${ }^{(2)}$.

Nos dois mapeamentos descritos e na construção do mapa da pessoa, considera-se mediadores colaboradores os humanos solidários, as pessoas de confiança ou as instituições, os quais são acionados nas demandas, nas solicitações e no desenvolvimento de estratégias e outros mecanismos para a mediação, exame, compreensão e resolução de conflitos e problemas. Sendo assim, podem ser internos ou externos à rede. E suas ações reforçam o empoderamento da rede, ou seja, a circulação de dons positivos que reforçam a aliança e o vínculo(2). 
Já os mediadores inibidores tem por características o fato que as suas ações reforçam o conflito, contribuem para a perpetuação dos problemas, perda da solidariedade grupal e da sinergia.

A MARES ainda permite que os sujeitos construam soluções para estas problemáticas, o que é chamado de saídas. Tendo em vista que a vida cotidiana no SRT requer de todos os envolvidos a construção de soluções para os impasses e conflitos na vida diária. Ou seja, aquelas situações que podem não ser favoráveis ao viver, como saudades, brigas, divisão de tarefas domésticas, trata-se, pois de pactuações e medidas a fim de superar os mediadores inibidores.

Este estudo foi aprovado pelo Comitê de Ética da Faculdade de Odontologia da UFPel, sob o parecer 073/2009, de 14 de janeiro de 2009. Todos os sujeitos do estudo concordaram em participar da pesquisa mediante a assinatura do Termo de Consentimento Livre e Esclarecido.

\section{RESULTADOS E DISCUSSÃO}

\section{Aplicação da MARES nos Serviços Residenciais Terapêuticos de Caxias do Sul}

A dinâmica de aplicação prática da MARES no contexto dos SRT's de Caxias do Sul contou com o apoio da técnica do grupo focal, a qual se desencadeou em três momentos: Mapeamento da Rede de Serviços, Mapeamento da Rede de Sociabilidade e Construção do Mapa da Pessoa - individual e coletivo.

No campo de Caxias do Sul foi entrevistado um total de 20 moradores nos dois SRT's em estudo, porém nem todos participaram dos grupos focais. Рara que se desenvolvesse a MARES com os moradores do SRT, primeiramente definiram-se alguns critérios de seleção dos sujeitos, a seguir descritos: concordar com a participação dos grupos e estar em boas condições de comunicação.

Portanto, foram identificados 11 moradores com essas características, os quais participaram dos grupos focais, sendo oito moradores do SRT 1 e três do SRT 2.

Também participaram quatro pesquisadores, dois destes realizaram observações e anotações, um pesquisador coordenava o grupo e outro auxiliava no desenvolvimento da atividade, e ainda contou-se com o auxílio da gravação de áudio dos três momentos que compõem a MARES.

Vale ressaltar que os encontros ocorreram no SRT 1, na lavanderia da casa (uma espécie de garagem) e tiveram a duração de em média uma hora. O local foi indicado pela equipe do serviço, por ser identificado como tranquilo e adequado para realização do grupo. Nesse espaço havia também um quadro de giz, que serviu como recurso visual.

Como recurso explicativo e didático, contou-se também com papel pardo para a confecção dos cartazes de cada grupo; pincel atômico nas cores azul, vermelho e preto; fita adesiva larga; lápis e borracha. Para explanar as questões referentes à rede de serviços e à rede social, foram confeccionadas cartões/placas que referenciavam cada serviço/instância.

\section{Primeiro momento: Mapeamento da Rede de Serviços}

Este primeiro momento teve como objetivo apreender as representações que os moradores do SRT tem sobre os condicionantes macrossociológicos, buscando compreender e sistematizar as crenças e valores gerais do usuário com relação à saúde.

O primeiro grupo ocorreu no dia 15 de maio de 2010, às $10 \mathrm{~h}$, com a participação dos 11 moradores escolhidos, e os quatro pesquisadores em campo. Teve duração de aproximadamente 45 minutos, com uma considerável participação de todos.

Houve dois momentos no desenvolvimento deste primeiro processo: fala introdutória para apresentação deste processo; e, mapeamento geral da rede de serviços do usuário.

O pesquisador teve como prioridade traduzir em linguagem acessível e coloquial os chamados fatores macrossociológicos nas situações acessíveis ao cotidiano.

Para atingir o objetivo do primeiro momento, foi utilizada a seguinte técnica: apresentação de um cartaz em papel pardo com a rede de serviços do usuário desenhada, baseada na discursividade das entrevistas e nas observações dos pesquisadores em campo, que condicionam o dia a dia do usuário na perspectiva da contribuição desta rede no processo de reabilitação psicossocial. Através das entrevistas realizadas foram identificados problemas em relação à rede que foram introduzidos no grupo e estes escolheram os que mais tinham significância a fim de elencar soluções. Foi feita a construção conjunta da rede, seus problemas e soluções 
encontradas e o fechamento do grupo.

Sendo assim, primeiramente identificou-se, através das observações realizadas pelos pesquisadores e das entrevistas dos moradores do SRT, a rede de serviços utilizada por eles no município de Caxias do Sul, e a partir de então se destacaram os problemas a fim de que fossem evidenciados no grupo focal. Entretanto alguns serviços foram percebidos como integrantes da rede, porém sem problemas aparentes, sendo citados no grupo para que os moradores pudessem identificar se havia ou não algum problema.

Os serviços são os seguintes: Ambulatório, Centro de Atenção Psicossocial (CAPS), Centro de Atenção Psicossocial Álcool e Drogas (CAPS ad), Hospital Psiquiátrico, leito em Hospital Geral, Pronto Socorro, Serviço Residencial Terapêutico (SRT) e Unidade Básica de Saúde (UBS). Esta rede pode ser exemplificada na Figura 1:

Figura 1: Ilustração da Rede de Serviços, baseada no Grupo Focal da MARES(2). Caxias do Sul, RS, 2010.

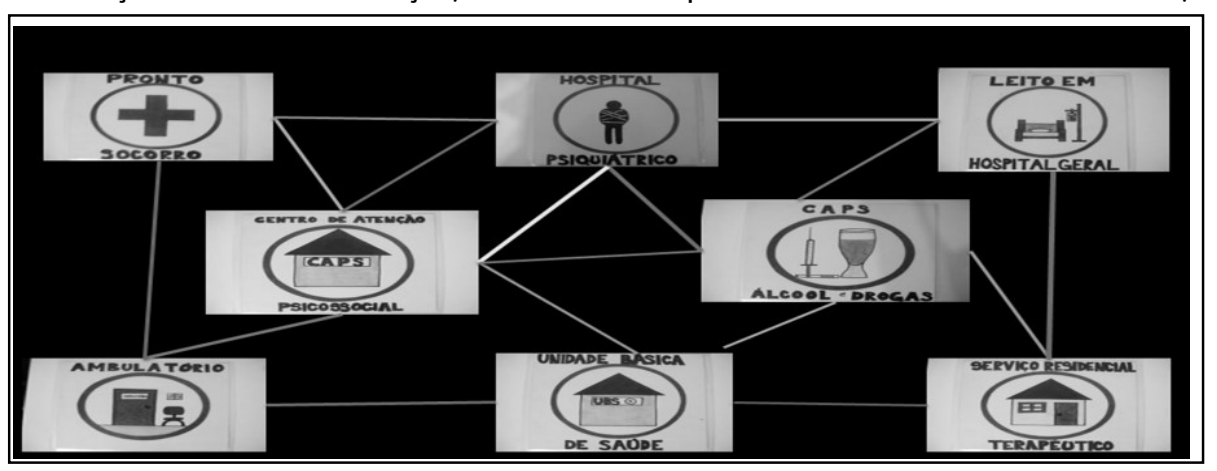

Em relatório publicado em 2001 sobre a saúde no contexto mundial, a Organização Mundial de Saúde (OMS) enfatiza que a saúde mental na atenção básica torna o atendimento mais efetivo, articula-o com os demais dispositivos da atenção à saúde, além de mobilizar a comunidade e ainda, ser economicamente favorável(9).

Os serviços de saúde mental existentes na maioria das cidades do Brasil tem se dedicado com obstinação à desinstitucionalização de indivíduos cronicamente asilados, às crises, ao tratamento de casos graves, dentre outras iniciativas. Entretanto, uma grande parte do sofrimento psíquico menos grave continua sendo objeto do trabalho da atenção básica e de ambulatórios e em qualquer uma de suas formas(10).

Percebe-se que a rede de saúde do município de Caxias do Sul contempla serviços que não se limitam somente às questões da saúde mental, podendo os moradores contar com serviços territorializados como Unidade Básica de Saúde, ambulatório e serviço de urgência e emergência.

Sendo assim, quanto ao grupo focal sobre o mapeamento dos serviços de saúde, inicialmente foi exposto pelos pesquisadores aos moradores cada serviço, individualmente, através dos desenhos das placas. Anteriormente ao grupo, foram confeccionadas tiras de papeis com os problemas e questionamentos, as quais iam sendo coladas sobre as placas após a citação do serviço, para que os moradores pudessem discutir se concordavam ou não com as afirmações, e que pudessem ao mesmo tempo, também elencar saídas. Os problemas/questionamentos podem ser visualizados na Quadro 1: 
Quadro 1: Mapeamento da Rede de Serviços de Saúde e seus problemas. Caxias do Sul, RS, 2010.

\begin{tabular}{|c|c|}
\hline Serviço & Problema \\
\hline Ambulatório (CAIS Mental) & Há algum problema? \\
\hline \multirow{2}{*}{ CAPS } & Não pode escolher as atividades. \\
\hline & Tem que participar das atividades quando não quer. \\
\hline CAPSad & Há dificuldade no tratamento no CAPSad? Por quê? \\
\hline Hospital Psiquiátrico (Clínica Paulo Guedes): & Maus tratos. \\
\hline $\begin{array}{l}\text { Leito em Hospital Geral: (CDQUIM [Centro de } \\
\text { Dependência Química] POA-RS): }\end{array}$ & É longe. Em outra cidade. \\
\hline Pronto Socorro & Demora no atendimento. \\
\hline SRT & $\begin{array}{l}\text { Não ter a liberdade que gostaria (escalas, saídas, chave, } \\
\text { banho, horário para acordar) }\end{array}$ \\
\hline UBS & Há dificuldade para ser atendido? \\
\hline
\end{tabular}

Nesse contexto foram identificados como mediadores colaboradores os seguintes serviços, acompanhados das compreensões relatadas pelos moradores: Leito em hospital geral: não há problemas em ser longe (em outra cidade), o atendimento é bom; CAPS ad: o tratamento é ótimo; CAIS Mental (ambulatório): o atendimento é ótimo; UBS: o atendimento é rápido.

Nesse sentido, evidencia-se, através das discussões dos moradores do SRT, que estes estão satisfeitos com relação ao atendimento recebido no CAPS ad, ambulatório e

Unidade Básica de Saúde.

Quanto aos mediadores inibidores, foram identificados pelos moradores do SRT de Caxias do Sul, os seguintes na rede de serviços de atenção psicossocial e apontadas as respectivas saídas para os problemas elencados: Pronto Socorro: há demora em ser atendido, é mal atendido. Saída: chamar o Serviço de Atendimento Móvel de Urgência (SAMU) porque é mais rápido; Hospital psiquiátrico: lá existe maus tratos para com os usuários. Saída: Tem que fechar, não existir; CAPS: não poder escolher as atividades, ter que participar das atividades quando não está com vontade. Saída: Pedir para a coordenadora do CAPS entregar as escalas escritas para cada um; SRT: não tem a liberdade que gostaria (chave para sair, escalas, horário para almoçar, é liberado somente um cigarro por vez). Saída: dar uma chave do SRT para cada morador; aumentar a renda mensal através da Oficina de Geração de Renda.

Por meio da identificação dos mediadores inibidores, pelos moradores do SRT de Caxias do Sul, percebe-se que há dificuldades com o serviço de Pronto Socorro, sendo que os moradores preferem acionar o SAMU ao invés de irem consultar no serviço de emergência.
Também há a referência dos moradores ao Hospital Psiquiátrico como componente da rede de saúde. Entretanto, estes afirmam que no âmbito desta instituição são maltratados e que a solução para que isso não aconteça é o fechamento deste serviço.

Para finalizar o grupo, cada morador foi convidado a desenhar no cartaz seu trajeto na rede, por meio da identificação de cada serviço que utiliza.

\section{Segundo momento: Mapeamento da Rede de Sociabilidade ${ }^{(2)}$.}

Este momento teve como objetivo apreender as representações que tem os usuários do SRT sobre os condicionantes microssociológicos, ou seja, aqueles responsáveis pela produção de seu bem-estar na sua reabilitação psicossocial. Buscou-se compreender e sistematizar as crenças e valores gerais do usuário com relação à sua rede social.

Este grupo ocorreu no dia 17 de maio de 2010, às 17h, no mesmo local em que ocorreu o primeiro grupo. Contou com a participação dos 11 moradores, e quatro pesquisadores do REDESUL. Teve duração de aproximadamente 50 minutos, com uma considerável participação de todos.

Рага o desenvolvimento deste grupo, foi utilizada uma lista de problemas antecipadamente emergidos das entrevistas do círculo dos moradores, sendo apresentado para estes mediante placas ilustrativas com os temas a serem apreciados. Esta etapa foi introduzida por uma exposição com duração de cerca de 15 minutos sobre a pesquisa e seus procedimentos.

Houve dois momentos neste segundo grupo focal. No primeiro houve uma fala introdutória para apresentação do trabalho. Inicialmente, explicou-se aos moradores 
como se desenvolveria o grupo, seus objetivos e finalidades. Em seguida iniciou-se o mapeamento geral da rede de sociabilidade do usuário, sendo fixado no quadro de giz o cartaz feito em papel pardo, o qual serviu de suporte para que fosse exposta a rede social dos moradores do SRT. A seguir, foram elencados os problemas baseados no discurso das entrevistas e também através da observação dos pesquisadores.

Foram identificados como integrantes da rede social dos moradores os seguintes lugares/instâncias e pessoas: amigos, hidroterapia, equoterapia, vizinhos, prefeitura, esporte, trabalho, família, banco, lazer, escola, supermercado. Estes podem ser exemplificados na Figura 2:

Figura 2: Ilustração da Rede de Serviços, baseada no Grupo Focal da MARES(2), Caxias do Sul-RS, 2010.

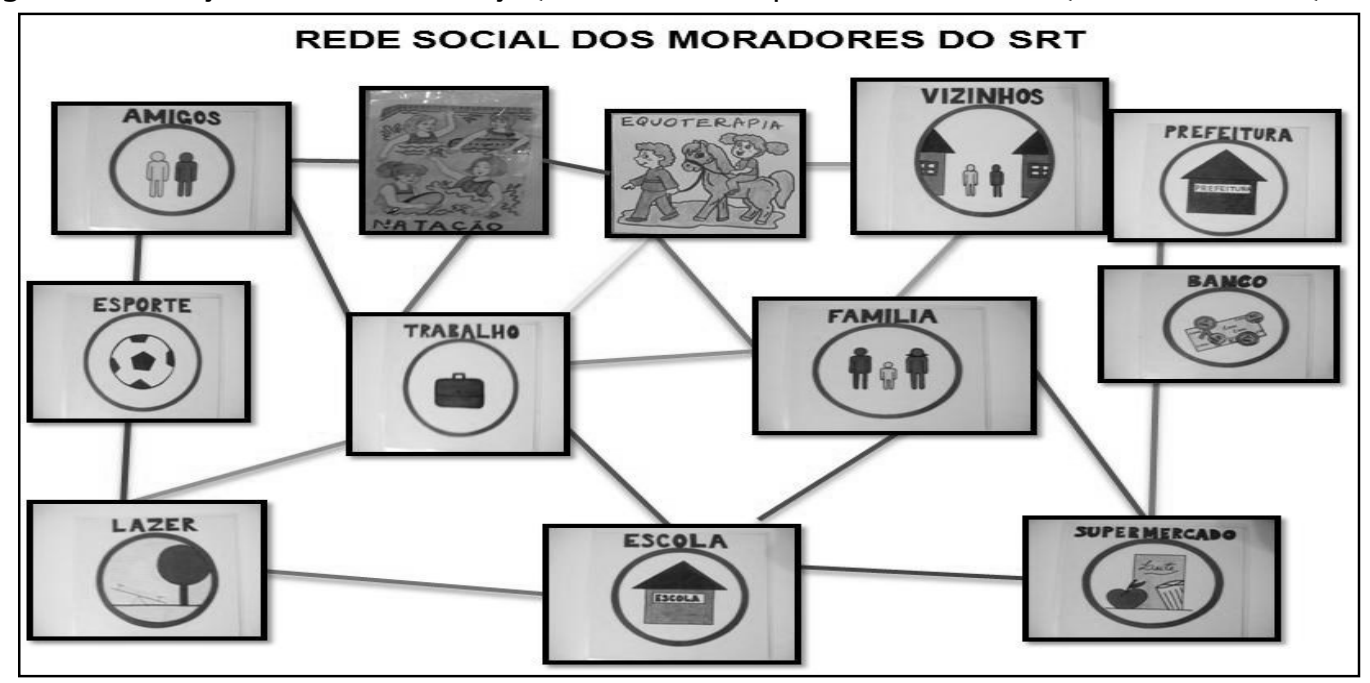

Uma rede pode ser definida como um conjunto de nós conectados, os quais podem ser pessoas ou grupos, ou outras unidades, e essas ligações podem ser assimétricas ou simétricas. E o termo rede social se remete ao conjunto de sujeitos em uma população e suas conexões. Cada indivíduo tem ligações com outros indivíduos, cada um dos quais, por sua vez, está ligado a muitos ou alguns outros, sendo assim por diante(11-12).

Redes também são estruturas abertas capazes de ampliar de forma ilimitada, integrando novos nós que consigam comunicar-se dentro da rede, ou seja, desde que compartilhem códigos semelhantes de comunicação. Uma estrutura social baseada em redes é, pois, um sistema aberto, extremamente dinâmico apto à inovação sem ameaças ao seu equilíbrio(12).

Sendo assim, a reabilitação psicossocial dos sujeitos de longa permanência institucional percorre intervenções e intersecções em variados campos, porque a integralidade do cuidado implica, além da moradia e da desinstitucionalização: reconstruções de histórias de vida, rede social, lazer, emprego, além de outras precisões que vão além da atenção possível, somente através da reorganização dos serviços ${ }^{(13)}$.
No estudo, redes sociais consistem em sistemas de trocas formados por fluxos incessantes de dons, de bens materiais e simbólicos que organizam os sistemas sociais e as próprias individualidades(1).

A compreensão teórica e política do usuário como sendo resultado histórico de redes em movimentação que ganham particularidades significantes em contextos sociais e culturais específicos ${ }^{(14)}$ permite analisar essa configuração no campo da saúde mental. As transformações oriundas do movimento da Reforma Psiquiátrica Brasileira remetem à necessidade de conhecer e avaliar os diversos serviços e estratégias de cuidado que, a partir de sua implantação consolidam, em alguns municípios, a rede de atenção em saúde mental. $A$ partir dessa rede é possível mapear o trânsito dos usuários, as relações que estabelecem entre si e com esses dispositivos, e o fluxo interacional entre os diversos atores neste cotidiano.

Durante o grupo focal, primeiramente, foi exposto aos moradores pelos pesquisadores as placas que expressavam cada local/pessoa. Os problemas/questionamentos podem ser vistos na Quadro 2: 
Quadro 2: Componentes da Rede Social dos moradores do SRT. Caxias do Sul, RS, 2010.

\begin{tabular}{|c|c|}
\hline Serviço & Problema \\
\hline Amigos & Às vezes tem conflitos, brigas. \\
\hline Banco & O benefício é pouco e não aumenta. \\
\hline Equoterapia & Há algum problema? \\
\hline Escola & Há algum problema com a escola? \\
\hline Esporte & Não faço todos os esportes que gostaria. \\
\hline Família & Não visita; sente saudade; há brigas com os familiares. \\
\hline Hidroterapia & Aostariam de sair mais? Em que lugares? \\
\hline Lazer & Há algum problema com a prefeitura? \\
\hline Prefeitura & Há algum problema com o supermercado? \\
\hline Supermercado & Se eu trabalhar, perco o benefício. \\
\hline Trabalho & Há algum problema com os vizinhos? \\
\hline Vizinhos &
\end{tabular}

Sendo assim, foram identificados os locais como contribuintes em sua reabilitação psicossocial, os mediadores inibidores e as saídas para os problemas: equoterapia: é ótimo; escola: é muito bom para aprender, o professor é bom; esportes: os esportes que fazem são o suficiente; prefeitura: é ótima, pagam o aluguel, a luz, fornecem alimentação diária; supermercado: compram o que querem, são bem atendidos.

Percebe-se uma ampliação da rede social dos moradores, no que se relaciona ao antes de residir no SRT e depois, sendo identificados como componentes dessa rede atividades de lazer, instituições de educação, a prefeitura e ainda o supermercado.

Ainda assim, como mediadores inibidores e as saídas para os problemas foram identificados os seguintes lugares/pessoas: Amigos: às vezes têm conflitos, brigas. Saída: conversar com os colegas; Banco (dinheiro): o benefício é pouco e não aumenta. Saída: conversar com as autoridades para que aumentem o benefício; Família: há brigas, não visitam os moradores no SRT, sentem saudades dos familiares. Saída: conversar com os familiares para que visitem mais vezes; Hidroterapia: alguns acham que a água da piscina é fria, enquanto outros não, a mensalidade é cara. Saída: conversar com a equipe para não ir mais à hidroterapia; Lazer: gostariam de viajar (ir a Gramado-RS, à praia). Saída: organizar passeios; Trabalho: se tiverem um emprego, perdem o benefício. Saída: - Oficinas de geração de renda; Vizinhos: os moradores às vezes ligam o som alto a noite, o que incomoda os vizinhos. Saída: - não ligar som alto a noite.

Рara encerrar o grupo focal, os moradores foram convidados a desenharem o seu trajeto no cartaz com as placas que expressavam os locais que faziam parte de sua rede social, construindo assim conjuntamente suas trajetórias individuais.

\section{Terceiro momento: Construção do Mapa da Pessoa - individual e coletivo}

O terceiro e último grupo focal aconteceu no dia 19 de maio de 2010, tendo início às 17 horas e duração de 45 minutos.

Рага a construção do Mapa da Pessoa Individual (Figura 3), participaram os 11 moradores que fizeram parte dos grupos focais. Os mapas foram construídos individualmente por cada sujeito, com a ajuda de um pesquisador. 
Figura 3: Mapa da Pessoa Individual(2). Caxias do Sul-RS, 2010.

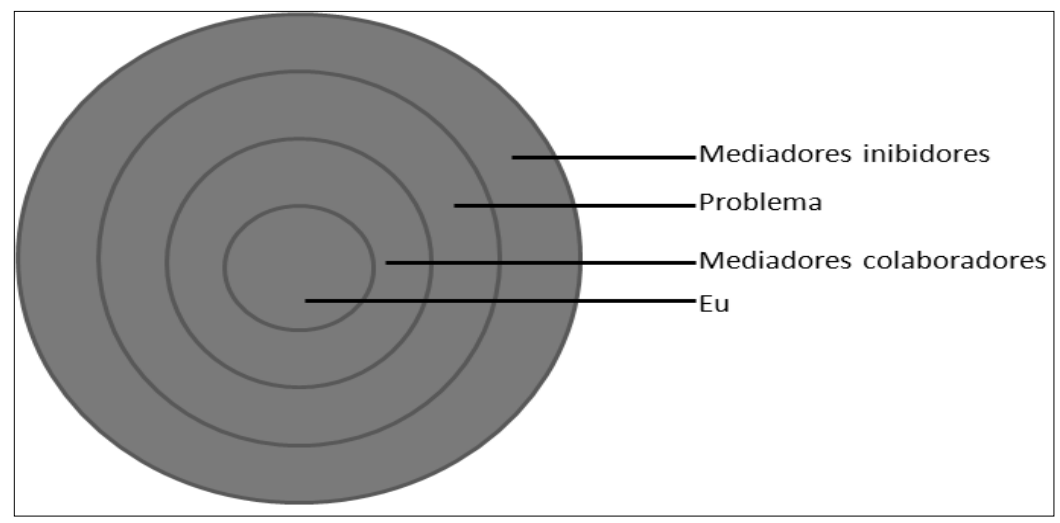

Em uma folha de ofício, no círculo mais interno colocava-se o nome do morador e a seguir era solicitado que o mesmo descrevesse um problema que fazia parte da sua vida e do seu cotidiano. A seguir, para esse mesmo problema era questionado ao morador um mediador colaborador, o qual the ajudava a transpor esse problema e, por conseguinte, um mediador inibidor, ou seja, o que proporcionava a perpetuação do seu problema. E para finalizar, o sujeito era estimulado a desenvolver uma saída para esse problema.

Portanto, por meio da construção de cada Mapa da
Pessoa Individual com os 11 moradores foram identificados 33 problemas, e destes selecionados os três mais citados, os quais estiveram expostos no último grupo focal, considerando-se a construção do Mapa da Pessoa Coletivo.

Na Quadro 3, para exemplificar a aplicação da MARES, pode ser evidenciado o Mapa da Pessoa Coletivo, através dos problemas que se sobressaíram e também da construção coletiva definida pelos moradores de seus mediadores colaboradores e inibidores.

Quadro 3: Mapa da Pessoa Coletivo, Caxias do Sul-RS, 2010.

\begin{tabular}{|c|c|c|c|}
\hline \multicolumn{4}{|c|}{ MAPA DA PESSOA COLETIVO } \\
\hline Problema & Mediadores inibidores & $\begin{array}{c}\text { Mediadores } \\
\text { colaboradores }\end{array}$ & Saídas \\
\hline \multirow{3}{*}{$\begin{array}{l}\text { Ter que cumprir as } \\
\text { tarefas/escalas no SRT, e se não } \\
\text { cumpre fica de castigo. }\end{array}$} & \multirow{3}{*}{$\begin{array}{l}\text { Escala muito próxima, } \\
\text { muitas atividades no } \\
\text { mesmo dia. }\end{array}$} & \multirow{3}{*}{$\begin{array}{l}\text { A vontade de realizar a } \\
\text { tarefa (limpar o pátio, } \\
\text { cozinhar etc.) }\end{array}$} & - Cumprir as tarefas; \\
\hline & & & $\begin{array}{l}\text { - A escala poderia ser } \\
\text { mais alternada; }\end{array}$ \\
\hline & & & $\begin{array}{l}\text { - Conversar com o } \\
\text { técnico de referência. }\end{array}$ \\
\hline $\begin{array}{l}\text { Gostaria de ter mais apoio da } \\
\text { família, que eles pudessem } \\
\text { visitá-los com mais frequência. }\end{array}$ & $\begin{array}{l}\text { Falta de tempo dos } \\
\text { familiares. }\end{array}$ & $\begin{array}{c}\text { Visitar os familiares } \\
\text { quando estes não vão até } \\
\text { o SRT. } \\
\end{array}$ & $\begin{array}{l}\text { Conversar com os } \\
\text { familiares para que os } \\
\text { visitem mais seguido. }\end{array}$ \\
\hline \multirow{3}{*}{$\begin{array}{c}\text { Brigas com os outros moradores } \\
\text { do SRT. Às vezes estes } \\
\text { incomodam muito. }\end{array}$} & \multirow{3}{*}{$\begin{array}{l}\text { Escutar rádio no volume } \\
\text { alto provoca brigas; o } \\
\text { jeito de cada um. }\end{array}$} & $\begin{array}{l}\text { - Os técnicos de } \\
\text { referência ajudam a } \\
\text { resolver; }\end{array}$ & $\begin{array}{l}\text { - Aconselhar os colegas } \\
\text { da casa a não brigarem; }\end{array}$ \\
\hline & & \multirow[t]{2}{*}{$\begin{array}{c}\text { - Conversar com os } \\
\text { amigos da casa. }\end{array}$} & $\begin{array}{l}\text { - Durante uma roda de } \\
\text { chimarrão, conversam } \\
\text { e se acertam; }\end{array}$ \\
\hline & & & - "Reatar os laços". \\
\hline
\end{tabular}

\section{CONCLUSÃO}

Compreender a rede de serviços e social dos moradores do Serviço Residencial Terapêutico através da Metodologia de Análise de Redes do Cotidiano (MARES), que foi desenvolvida e sistematizada pelo sociólogo Paulo Henrique Martins, mostrou-se eficaz para visualizar e compreender as redes dos moradores do SRT, visto que se trata de uma metodologia potente para analisar as redes de serviços de atenção psicossocial, e as redes sociais que se constituem no cotidiano destes usuários de saúde mental ao longo do processo de mudança neste campo.

A MARES tem importância investigativa porque permitiu desenhar as redes dos sujeitos que utilizam os 
serviços de saúde mental, articulando informações subjetivas e objetivas, e em seu caráter construcionista permitiu que os integrantes da pesquisa se apropriem das informações tornando-se mediadores e multiplicadores de processos sociais coletivos. É uma metodologia que

\section{REFERÊNCIAS}

1. Martins $P$. As redes sociais, o sistema da dádiva e o paradoxo sociológico. In: Martins PH, Fontes B, editors. Redes sociais e saúde: novas possibilidades teóricas. Recife: Editora Universitária da UFPE; 2008. p. 9-17.

2. Martins P. MARES (Metodologia de Análise de Redes do Cotidiano): aspectos conceituais e operacionais. In: Pinheiro R.; Martins PH, editors. Avaliação em saúde na perspectiva do usuário: abordagem multicêntrica. Rio de Janeiro: CEPESC/IMSUERJ; Recife: Editora Universitária UFPE; São Paulo: ABRASCO; 2009. p. 61-89.

3. Martins PH. A dádiva entre os modernos: discussão sobre os fundamentos e as regras do social. Petrópolis: Vozes; 2002. 4. Amarante PDC, Torre EHG. Avaliação em saúde mental: da mensuração diagnóstica e psicopatológica em direção à complexidade no campo da saúde e das políticas públicas. In: Pinheiro R, Guljor AP, Silva Júnior AG, Mattos RA, editores. Desinstitucionalização da saúde mental: contribuições para estudos avaliativos. 1std ed. Rio de Janeiro: CEPESC - IMS/UERJ - ABRASCO; 2007. p. 65-90.

5. Guedes AC, Kantorski LP, Pereira PM, Clasen BN, Lange C, Muniz RM. A mudança nas práticas em saúde mental e a desinstitucionalização: uma revisão integrativa. Rev. eletr. enferm. 2010;12(3):547-53.

6. Ludke M; André MEDA. Pesquisa em educação: abordagens qualitativas. São Paulo: EPU; 1986.

7. Yin RK. Estudo de caso: planejamento e métodos. 3std ed. Grassi D translator. Porto Alegre: Bookman; 2005.

8. lervolino AS, Pelicioni MCF. A utilização do grupo focal como metodologia qualitativa na promoção da saúde. Rev Esc Enferm USP. 2001;35(2):115-21.

9. Organização Mundial da Saúde WHO. Atlas de salud mental em el mundo 2001. Determinantes de la Salud Mental y Poblaciones Departamento de Salud Mental y Toxicomanías Organización Mundial de la Salud. Ginebra; 2001.

10. Ministério da Saúde; Coordenação de Saúde Mental e Coordenação de Gestão da Atenção Básica. Saúde mental e atenção básica: o vínculo e o diálogo necessário. Brasília (Brasil): Ministério da Saúde; 2003.

11. Barbosa MTS, Byington MRL, Struchiner CJ. Modelos dinâmicos e redes sociais: revisão e reflexões a respeito de sua contribuição para o entendimento da epidemia do HIV Cad. Saúde Pública. 2000;16(1):37-51.

12. Castells MA. Sociedade em Rede. A era da informação: economia, sociedade e cultura. 1std ed. São Paulo: Paz e Terra; 2007.

13. Pinheiro R. As práticas do cotidiano na relação oferta e demanda dos serviços de saúde: um campo de estudo e construção da integralidade. 2010 [acesso em: 29 mar 2013]. Disponível em:

http://www.lappis.org.br/cgi/cgilua.exe/sys/start.htm?sid=25\&i nfoid=149\&tpl=view_participantes.

14. Martins PH, Fontes $B$. Redes sociais e saúde: novas possibilidades teóricas. 2. ed. Recife: Ed. Universitária da UPFE; 2008. 159p. valoriza a experiência do usuário no cotidiano; as trocas que estabelece, os conflitos e alianças; e permitiu apontar saídas que além de fortalecerem a pessoa individualmente, contribuem para a construção coletiva e para o senso comunitário.

Artigo recebido em 11/11/2011

Aprovado para publicação em 12/04/2012.

Artigo publicado em 31/03/2013. 